\title{
ULTRAESTRUTURA DA ESPERMATOGÊNESE DO TAMOATÁ, HOPLOSTERNUM LITTORALE (HANCOCK) (TELEOSTEI, CALLICHTHYIDAE) DO RIO AMAZONAS
}

\author{
E. Matos 1 \\ P. Matos 1 \\ E. Oliveira 2 \\ C. Azevedo ${ }^{2}$
}

\begin{abstract}
ULTRASTRUCTURE OF THE SPERMATOGENESIS OF THE FISH, HOPLOSTERNUM LITTORALE (HANCOCK) (TELEOSTEI, CALLICHTHYIDAE) OF THE AMAZON RIVER. Sequential cytological modifications of Hoplosternum littorale (Hancock) spermatogenesis were studied with electron microscopy from the spermatocyte to the mature spermatozoon. Five stages of spermatical maturation were described. The spermatozoon is one of the primitive tupe, with head without acrosome and a tail with a type pattern. KEY WORDS. Teleostei, Callichthyidae, Hoplosternum littorale
\end{abstract}

Numerosos estudos de morfologia ultraestrutural sobre espermatogênese, e especialmente de espermatozóides, tem sido realizados em diversas espécies de peixes, de diferentes áreas geográficas (STANLEY, 1969; MATTEI, 1970; MATTEI \& MATTEI, 1973, 1978; GRIER, 1973; BILLARD, 1983, 1986; LAHNSTEINER et al. 1991), limitados a determinados aspectos, sem uma visão global do processo espermatogênico dos teleósteos. No caso de peixes da região amazônica, pouco tem sido feito quanto à ultraestrutura da espermiogênese e da produção de células espermáticas (LANDIM e HÖFLING, 1986; MATOS e AZEVEDO, 1989).

O tamoatá é, sem dúvida, uma das espécies ictíicas mais rústicas encontradas na região amazônica. Este peixe, como os demais da família Callichthyidae, consegue sobreviver em águas com baixo teor de oxigênio e poluídas, além de sobreviver por períodos longos em reduzidos volumes de água ou até por algumas horas fora do ambiente aquático (IHERING, 1968). Através destas características principais, a espécie em questão demonstra ser bastante resistente, permitindo sua utilização e manuseio por determinado período de tempo, sem apresentar modificações ou danos de ordem biológica.

Verifica-se que, durante o período da seca na região amazônica, em função da redução no volume de água, podemos encontrar, juntamente com

1) Departamento de Histologia e Ermatologia, Universidade do Pará, 66059-900 Belém, Pará, Brasil.

2) Departamento de Biologia Celular, Universidade do Porto, 4000 Porto, Portugal. 
outras espécies piscícolas, grande quantidade de tamoatás no leito de lagos e rios. Observa-se que, durante o início das cheias, esses peixes procuram as áreas recém-inundadas, preferencialmente com pouca profundidade, onde, protegidos por vegetação aquática pequena, iniciam a desova e permanecem durante quase todo o período da cheia (TUMA, 1978).

Com a finalidade de estudar-se o desenvolvimetno espermático destes peixes, destacou-se o aspecto ultraestrutural da espermatogênese, acreditando ser de importância o conhecimento do amadurecimento espermático, inclusive para o aconselhamento de projetos de povoamento aquático com esta espécie.

O presente estudo descreve, por meio da microscopia eletrônica, detalhes da estrutura fina do espermatozóide de Hoplosternum littorale, peixe de relativa abundância na comercialização em nossa região, contribuindo no conhecimento da produção das células gametogênicas, onde praticamente muito pouco tem sido feito em peixes brasileiros.

\section{MATERIAL E MÉTODOS}

Espécimes de Hoplosternum littorale (Hancock, 1828) Eig \& Eig, 1988 (Teleostei, Callichthyidae) foram coletados de rios nos arredores de Belém, Pará, durante o período de cheias, em que se processa o amadurecimento gonadal. Pequenos fragmentos de testículos foram fixados em glutaraldeídeo a $3 \%$ em tampão cacodilato de sódio $0,1 \mathrm{M}$ a pH 7,2 a $4^{\circ} \mathrm{C}$ durante duas horas. Após lavagem no mesmo tampão durante duas a três horas a $4^{\circ} \mathrm{C}$, os citados fragmentos foram pós-fixados em tetróxido de ósmio a $2 \%$ no mesmo tampão, a $4^{\circ} \mathrm{C}$ durante duas horas. $\mathrm{O}$ tecido foi então desidratado em série crescente de álcool etílico, seguido de três trocas de óxido de propileno. A inclusão foi feita em Epon, os cortes semi-finos e ultra-finos em ultramicrótomo com faca de vidro e diamante, e a dupla contrastação com solução aquosa saturada de acetato de uranila e citrato de chumbo (AZEVEDO et al., 1985). As grelhas contendo os cortes foram examinados e fotografados no microscópio eletrônico de transmissão JEOL 100 CXII, operando a $60 \mathrm{Kv}$.

\section{RESULTADOS}

Durante a maturação sexual, o testículo do tamoatá apresenta a organização típica de teleósteos. Os túbulos seminíferos são constituidos de cistos espermatogênicos delimitados por camada única de células, correspondentes às células de Sertoli. As células germinativas dentro de cada cisto espermático, desenvolvendo sincronicamente todos os estágio da espermatogênese, são facilmente identificáveis, e à medida que os espermatozóides amadurecem nos cistos, são liberados na luz do túbulo seminífero (Figs 1 e 2).

Quando os cistos apresentam somente espermatogônias, existem poucas células, entretanto nos cistos em que a espermatogênese está presente encontramos numerosas células unidas por pontes citoplasmáticas, inclusive entre as espermátides em diferenciação. 

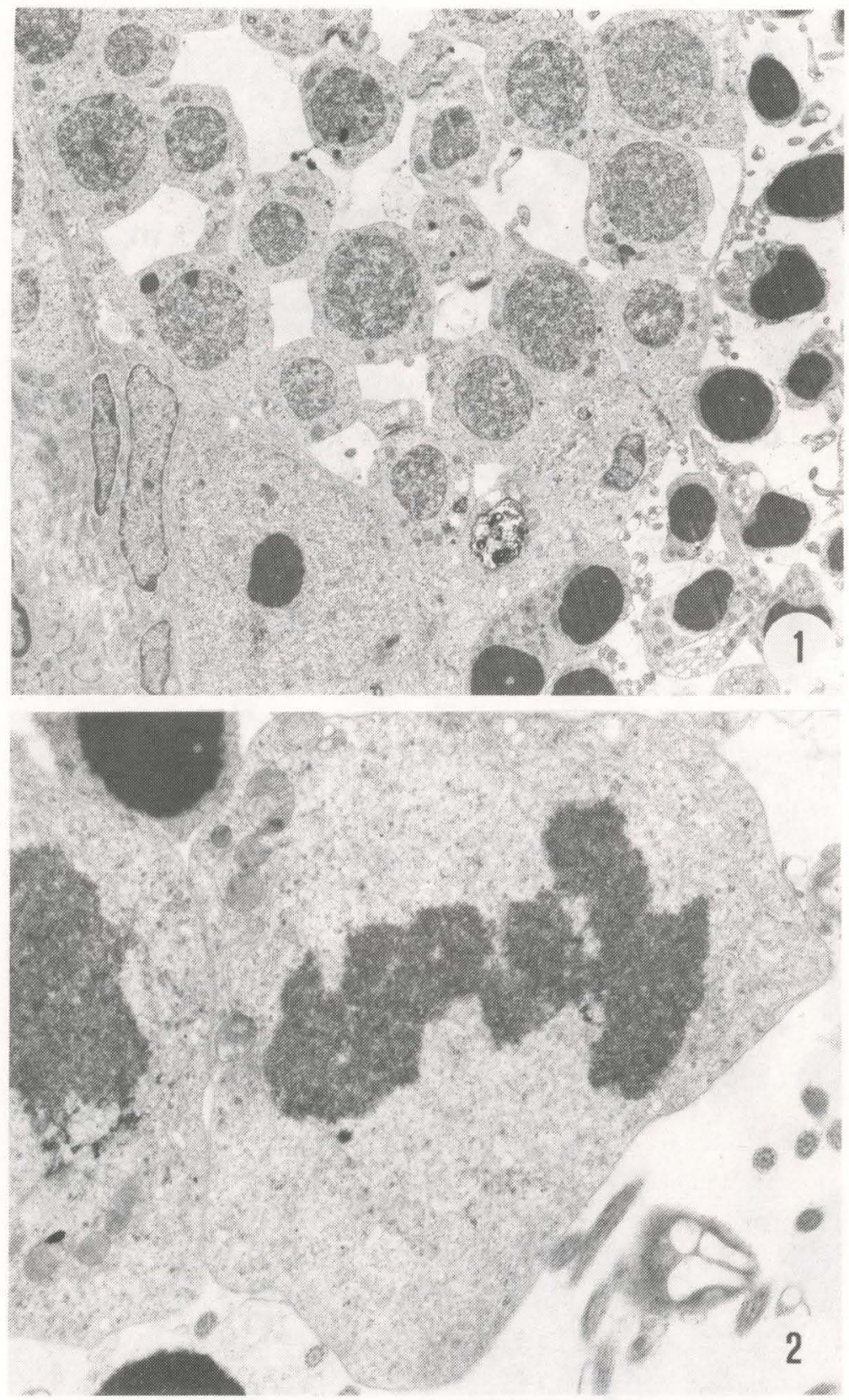

Figs 1-2. (1) Eletromicrografia do testículo de tamoatá. Observa-se no túbulo seminífero diferentes planos de células germinais em diferentes fases de desenvolvimento (aumento de 4700x); (2) aspecto de uma espermatogônia em divisão mitótica (metáfase) (aumento de 14400x). 

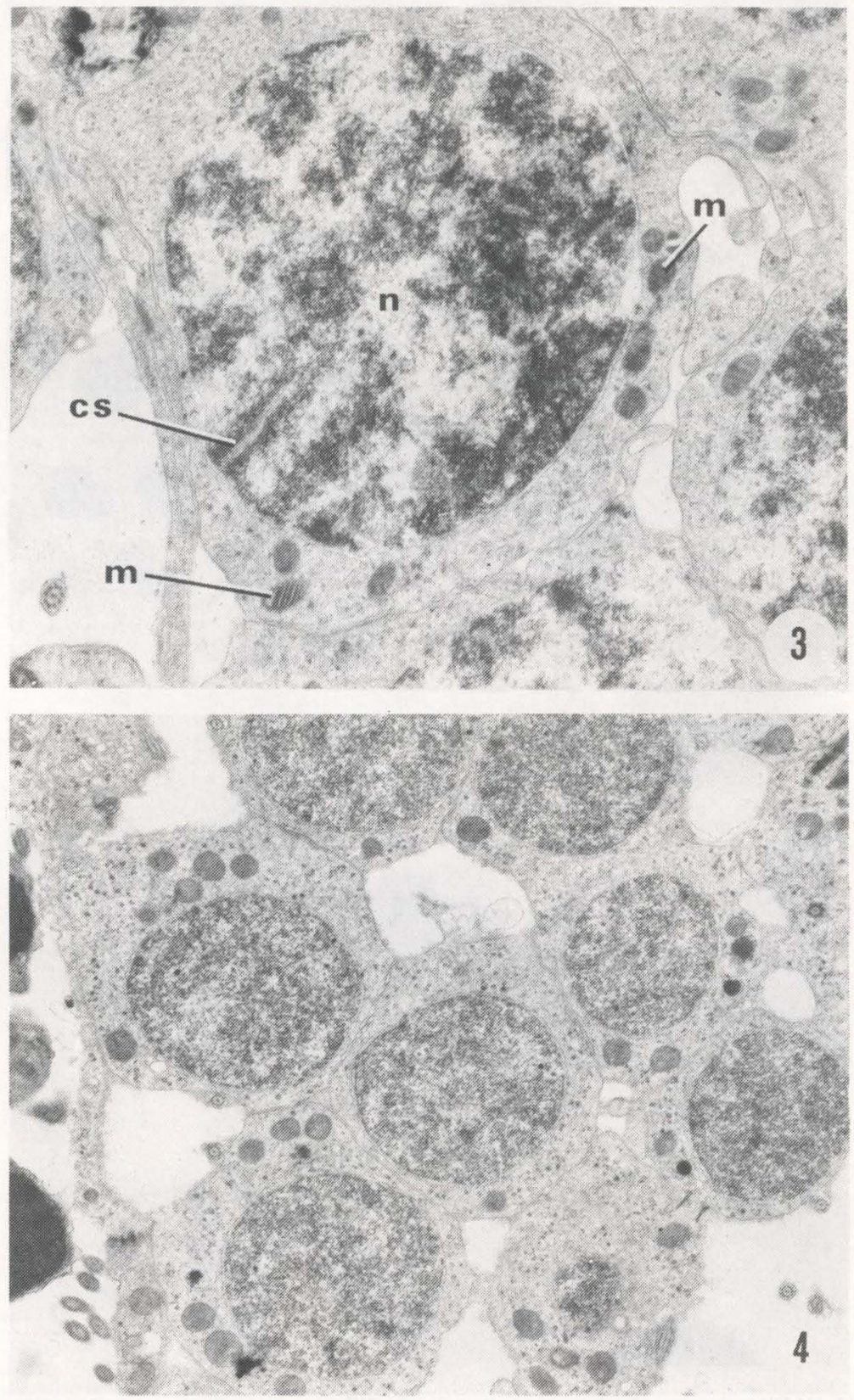

Figs 3-4. (3) Eletromicrografia de pormenor ultraestrutural de espermatócito I em zigóteno (m) mitocôndria, (n) núcleo, (cs) complexo sinaptonêmico (aumento de 17000x); (4) grupo de espermatócitos II em início da fase de espermiogênese (aumento de 9000x). 
Durante a fase de amadurecimento das espermátides podemos distinguir cinco tipos celulares diferentes, caracterizados particularmente por mudanças nucleares que são consideradas como estágios de maturação.

Primeiro estágio (I). É constituido por espermátides agrupadas dentro dos cistos espermáticos, ligadas por pontes citoplasmáticas, apresentando aproximadamente o mesmo tamanho dos espermatócitos primários e secundários (Figs 3 e 4), com núcleo esférico e grande em relação ao volume do citoplasma. A cromatina apresenta-se irregularmente condensada, o nucléolo é volumoso. No citoplasma encontra-se, mitocôndrias, dictiosomas (complexo de Golgi), centríolos e pouco retículo endoplasmático granular (Fig.5).

Segundo estágio (II). Apresenta as espermátides com as mesmas características, mas a cromatina está condensada uniformemente sob a forma de grânulos homogêneos, com pequenos e esparsos agrupamentos de grânulos ocasionais. As mitocôndrias apresentam-se esféricas e agrupadas no citoplasma, próximo ao núcelo. Observamos presença de polissomas.

Terceiro estágio (III). As espermátides são menores que as anteriores, ligadas por pontes citoplasmáticas. O núcleo é esférico, porém com cromatina menos densa e com formação de diversas regiões de condensação ligeiramente alongada. A quantidade de citoplasma em redor do núcleo apresenta-se mínima onde os seus constituintes deslocam-se para um dos polos da célula, incluindo o centríolo a partir do qual se alonga um flagelo. O dictiosoma não é mais observado (Fig. 6).

Quarto estágio (IV). A espermátide deixa de apresentar núcleo esférico, sofrendo uma endentação no polo em que se encontra em contacto com o centríolo. Cromatina sob a forma de grumos grosseiros interligados por filamentos no polo oposto ao centríolo. Citoplasma estendido ao redor da parte inicial do flagelo, formando bainha, onde são evidenciadas mitocôndrias.

Quinto estágio (V). O desenvolvimento das espermátides, se caracteriza pela completa compactação da cromatina nuclear. O núcleo apresenta-se ligeiramente reniforme e contornos levemente irregulares. Poucas mitocôndrias se agrupam em redor dos centríolos e a bainha citoplasmática se afina restando membranas plasmáticas justapostas.

Os espermatozóides, formandos por esse processo de amadurecimento das espermátides, podem ser basicamente divididos em cabeça e cauda. Este espermatozóide é considerado do tipo primitivo não tendo acrossomo e nem peça intermediária bem definida.

A cabeça é formada pelo núcleo em forma de rim, de alta densidade eletrônica. Na reentrância basal do núcleo localizam-se dois centríolos: o proximal dentro da depressão, e o distal que dá origem ao flagelo.

A cauda é constituída essencialmente pelo flagelo envolvido em seu terço inicial por uma bainha formada praticamente só pelas membranas justapostas. O flagelo é do tipo axonêmico $9 p+2$ e apresenta também fino envoltório citoplasmático que se expande formando alargamentos laterais, com imagens diferenciadas na sua composição (Figs 7 e 8 ). 

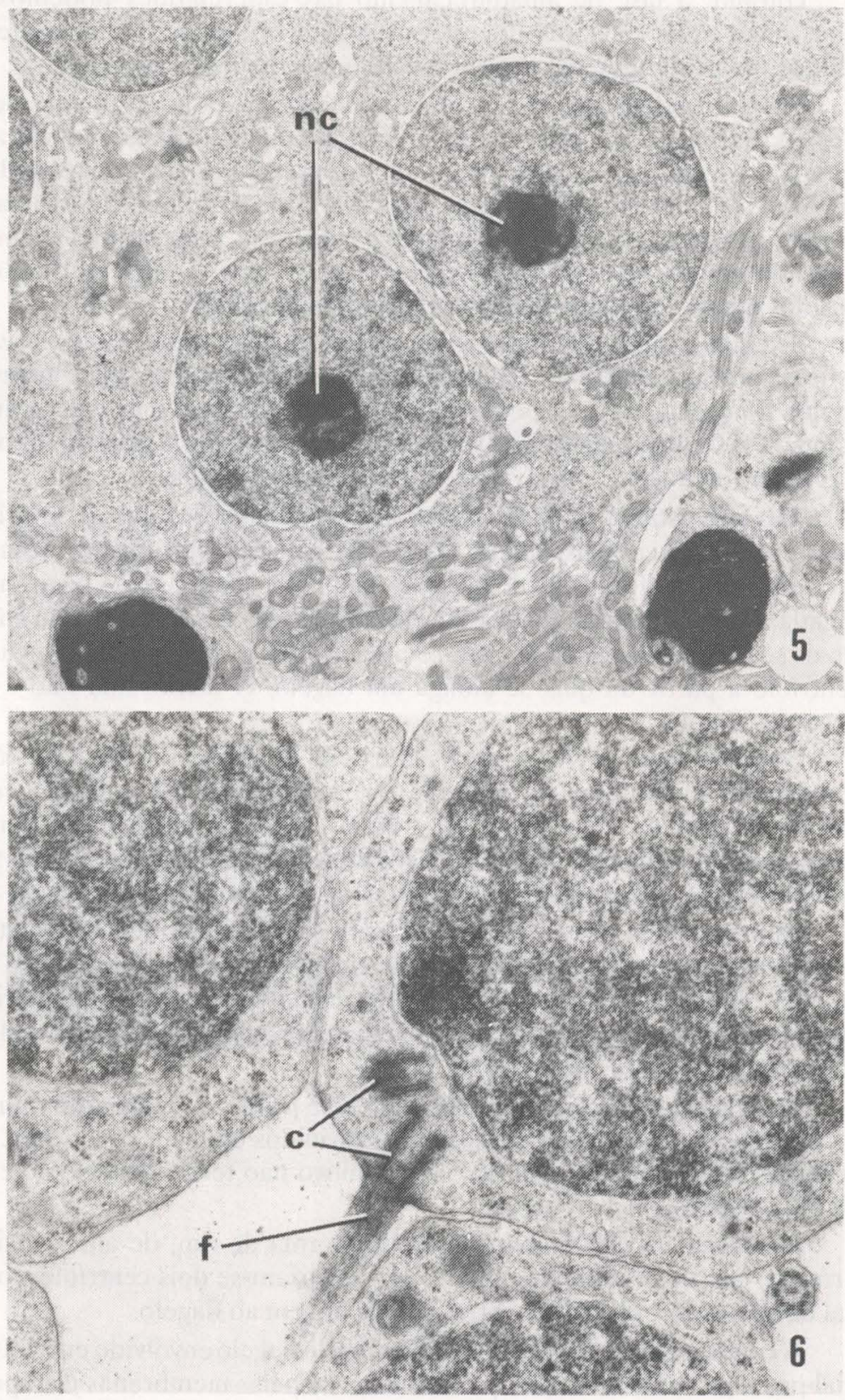

Figs 5-6. (5) Pormenor ultraestrutural de dois espermatídeos jovens, em que se observam os nucléolos (nc) volumosos (aumento de 7200x); (6) pormenor ultraestrutural de espermatídeos médios, em que se observa a presença de um flagelo (f) e dois centríolos (c) (aumento de 27200x).

Revta bras. Zool. 10 (2): 219-227, 1993 

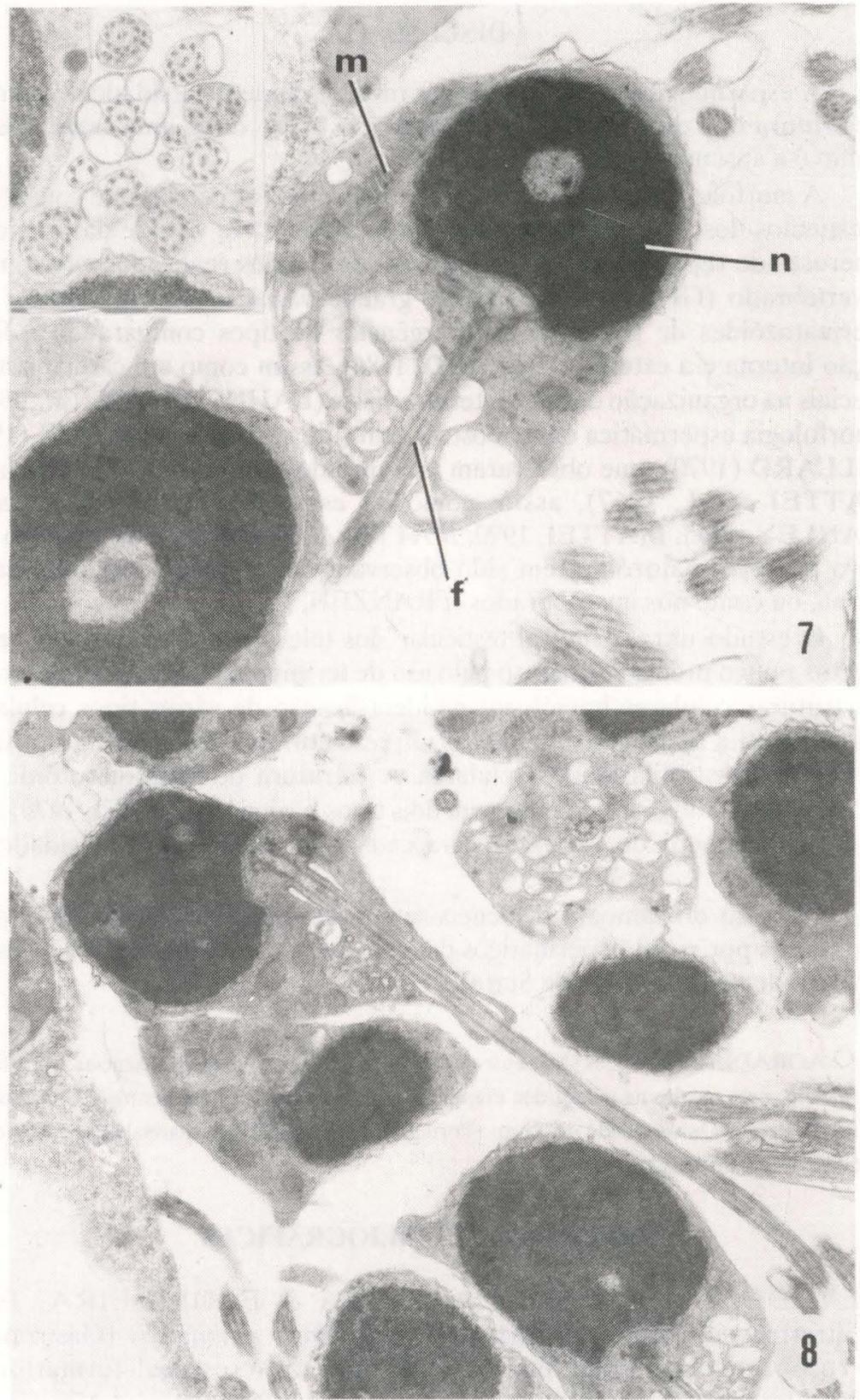

Figs 7-8. (7) Espermatídeo tardio na fase final ta espermiogênese, no qual se observa o núcleo (n) denso, mitocôndrias (m) e flagelo (f) (aumento de 22000x); Inset: corté transversal de flagelos mostrando o axonema ( $9 p+2$ pares de microtúbulos) (aumento de $23400 x)$; (8) Grupo de espermatozóides, segundo vários planos de corte, situados no lúmen dos túbulos seminíferos (aumento de $14300 x)$. 


\section{DISCUSSÃO}

A espermiogênese dos teleósteos revela grande diversidade de forma e de estrutura dos espermatozóides (MATTEI, 1970), onde uma característica comum é a ausência de acrossomo.

A morfologia e homologia dos diferentes tipos de células que constituem os testículos dos teleósteos, é muito pouco evidente em virtude das maneiras numerosas de reprodução que comprovam os estudos realizados neste grupo de vertebrado (GRIER, 1981). Existe grande variação na organização dos espermatozóides de peixes, com divergências de tipos comparando a fertilização interna e a externa (BILLARD, 1986), assim como em características especiais na organização da peça intermaediária (LAHNSTEINER et al., 1991). A morfologia espermática em teleósteos tem sido revista por MATTEI (1970) e BILLARD (1970), que observaram presença de espermatozóides flagelados (MATTEI et al., 1967), assim como de espermatozóides biflagelados (STANLEY, 1965; MATTEI, 1970; MATTEI \& MATTEI, 1978). O tipo primitivo de espermatozóide tem sido observado em animais com fertilização externa, ou como nos invertebrados (FRANZEN, 1970).

O estudo ultraestrutural testicular dos teleósteos, tem sido em certos aspectos pouco preciso e confuso pelo uso de terminologia variada à descrição de estruturas celulares homólogas na identificaçào de vários tipos celulares. Inclusive com a aplicação de técnicas ultraestruturais é que tem sido possível resolver muitas similaridades celulares. A estrutura do espermatozóide dos teleósteos tem sido dividida então em dois tipos básicos (MATTEI, 1970) com um grande número de variantes pâra cada tipo, diante da diversidade reprodutiva.

No caso do tamoatá evidencia-se a presença de túbulos seminíferos, constituídos por cistos espermáticos delimitados por camada única de células, correspondentes às células de Sertoli.

AGRADECIMENTOS. Ao Setor de Piscicultura da Faculdade de Ciências Agrárias do Pará, Belém, pelo auxílio na coleta dos exemplares. Acordo Internacional entre a Universidade Federal do Pará e Universidade do Porto (Portugal). Este trabalho foi parcialmente subsidiado pela CME-INIC, Portugal.

\section{REFERÊNCIAS BIBLIOGRÁFICAS}

AZEVEDO, C.; A. LOBO-DA-CUNHA \& E. OLIVEIRA. 1985. Ultrastructure of the spermatozoon in Gibbula umbilicalis (Gastropoda, Prosobranchia), with special refverence to acrosomal formation. J. Submicrose. Cytol.: 609-614.

BILLARD, R. 1970. Ultrastructure comparée des spermatozoides de quelques poissons téléostéens p. 71-79. In: B. BACCETTI (ed.). Comparative Spermatology. New York, Academic Press.

. 1983. Spermiogenesis in the rainbow trout (Salmo gairdneri). An 
ultrastructural study. Cell Tissue Res. 233: 265-284.

-1986. Spermatogenesis and spermatology of some teleost fish species. Reprod. Nutr. Dev. 26: 877-920.

FRANZEN, A. 1970. Phylogenetic aspects of the morphology of spermatozoa and spermiogenesis, p. 29-46. In: B. BACCETTI (ed.). Comparative Spermatology. New York, Academic Press.

GRIER, H.J. 1973. Ultrastructure of the testis in the teleost Poecilia latipinna. Spermiogenesis with reference to the intercentriolar lamellated body. $\mathbf{J}$. Ultrastruct. Res. 45: 82-92.

-1981. Cellular organization of the testis and spermatogenesis in fishes. Amer. Zool. 21: 345-357.

IHERING, R. VON. 1968. Dicionário dos animais do Brasil. São Paulo, Ed. Universidade de Brasília, $2^{\mathrm{a}}$ ed., 666p.

LAHNSTEINER, F.; R.A. PATZNER \& T. WEISMANN. 1991. The fine structure of spermatozoa of the grayling, Thymallus thymallus (Pisces, Teleostei). J. Submicrosc. Cytol. Pathol. 23 (3): 373-377.

LANDIM, C.C. \& M.A.C. HÖFLING. 1986. Aspectos da espermatogênese de tucunaré, Cichla ocellaris Schneider, 1801 (Teleostei, Cichlidae). Acta Amazonica 16/17: 65-72.

MATOS, E. \& C. AZEVEDO. 1989. Estudo ultraestrutural da espermatogênese de Lepidosiren paradoxa (Pisces, Dipnoi) da Amazonia. Rev. Bras. Ciênc. Morfol. 6 (2): 67-71.

MATTEI, C. \& X. MATTEI. 1973. La spermiogènese d'Albula vulpes (L. 1758) (Poisson, Abulidae). Étude ultrastructurale. Z. Zellforsch. 142: 171-192.

— 1978. La spermiogènese d'un poisson Téléostéen (Lepadogaster lepadogaster). I. La spermatide. Biol. Cellulaire 32: 257-266.

— 1978 La spermiogènese d'un poisson Téléostéen (Lepadogaster lepadogaster). II Le spermatozoide. Biol. Cellulaire 32: 267-274.

MATTEI, X. 1970. Spermiogenèse comparée des poissons, p. 57-84. In: B. BACCETTI (ed.). Comparative Spermatology. New York, Academic Press. MATTEI, X.; C. BOISSON; C. MATTEI \& C. REIZER. 1967. Spermatozoides aflagellés chez un Poisson: Gymmarchus viloticus (Téléostéen, Gymmarchidae). C.R. Acad. Sci. 265: 2010-2012.

STANLEY, H.P. 1965. Electron microscopic observations on the biflagellate spermatids of Porichthys nolatus. Anat. Rec. 151: 477.

. 1969. An electron microscope study of spermiogenesis in the teleost fish Oligocottus maculosus. J. Ultrastruct. Res. 27: 230-243.

TUMA, Y.S. 1978. Contribuição para o conhecimento da biologia do tamoatá Hoplosternum littorale (Hancock, 1828) Eigenmam \& Eigenmam, 1888 (Pisces, Callichthyidae), da Ilha do Marajó, Pará - Brasil. Boletim da FCAP., Belém (10): 59-76.

Recebido em 15.V.1991; aceito em 25.XI.1993. 